Brit. J. industr. Med., 1960, 17, 141.

\title{
STUDIES ON THE CHEMICAL FORMS OF URINARY LEAD
}

\author{
BY \\ G. T. DINISCHIOTU, B. NESTORESCU, I. C. RADULESCU, C. IONESCU, N. PREDA, \\ and G. ILUTZA

\begin{abstract}
From the Clinic for Occupational Diseases of the University of Bucharest and the Clinical Section of the Hygiene and Public Health Institute of Rumania, Colentina Hospital, Bucharest
\end{abstract}

(RECEIVED FOR PUBLICATION AUgUST 11, 1959)

\begin{abstract}
Lead in urine has been determined by an ashing technique to give total lead and by a standard coprecipitation technique to give precipitable lead. In 44 normal subjects values obtained by both methods were the same. In 72 subjects exposed to lead, of whom 57 had clinical lead poisoning, the precipitable lead was significantly less than the total lead. As much as $40 \%$ of urinary lead can escape determination by the coprecipitation methods of estimation. Preliminary findings suggest that the non-precipitable lead may be present as a natural chelate. The significance of these observations is discussed. The danger is stressed that cases of threatened lead intoxication may be overlooked if only coprecipitation methods of estimating lead in urine are used.
\end{abstract}

In many cases of lead poisoning we have been surprised to find no correlation between the values of the blood lead and those of the urinary lead excretion. This has been reported by others (Kehoe, Thamann, and Cholak, 1933a and b), but the observations have not yet been interpreted. While some place reliance on blood lead levels in the diagnosis of lead poisoning, others place more value on the level of urinary excretion (Litzner and Weyrauch, 1932; Gorn and Fridland, 1955).

We have also frequently found during our investigations in the lead industry that in certain plants there were considerable differences between the degree of the workers' exposure to lead whereas the figures for their urinary lead excretion were very similar. Furthermore we observed in cases of lead poisoning that, while the levels of blood lead lay within relatively narrow limits, the urinary lead values showed large differences.

In all these studies the method used to determine urinary lead was the spectrophotometric determination of the dithizone complex after preliminary coprecipitation of the lead from the urine.

Undoubtedly the best procedure for estimating lead is to ash the sample in order to bring all the lead into the mineral form most suited for the subsequent determination. But this process is laborious and time-consuming and a more rapid and simpler procedure of separation was sought. This was attained by the coprecipitation of lead with an excess of a mineral salt-oxalate, phosphate, or carbonate (Fairhall, 1924; Fairhall and Keenan, 1941; Rosenqvist, 1942; Kaye, 1943). Cholak, Hubbard, and Burkey (1948) established the method in a practical form which has been widely used (Amdur, 1953). This method is well suited for clinical observation of chronic lead poisoning and for the screening of workers in plants with a potential exposure to lead.

However, under some conditions the quantitative separation of the urinary lead may not be obtained by coprecipitation. For instance, in tetraethyl lead poisoning where the lead is partly excreted in an organic form, Woessner and Cholak (1953) have modified the method by introducing an oxidation process to break down the organic compounds. In the course of treatment of lead poisoning with versenates (E.D.T.A.) lead is eliminated as a chelate complex which does not precipitate (Hardy, Elkins, Ruotolo, Quinby, and Baker, 1954). In such cases a preliminary ashing is recommended (Bessmann and Layne, 1955). Thus under certain conditions the urinary lead can undoubtedly partly escape determination by the coprecipitation process.

\section{Methods}

We have followed systematically the urinary lead excretion in 44 healthy individuals with an exposure to lead no. greater than that of normal living conditions ("physiological lead absorption") and in 72 individuals 
heavily exposed to lead during their work ("increased industrial absorption"). Of these, 15 showed no clinical or laboratory signs of lead poisoning. The other 57 cases were diagnosed both clinically and on the basis of laboratory findings as suffering from "chronic evolutive lead poisoning" of different degrees (Dinischiotu, Rădulescu, Preda, and Georgescu, 1959). Of these 17 had lead colic.

The urinary lead of all the subjects was determined after wet ashing with nitric and perchloric acids by the method of Bessman and Layne (1955) to give "total lead" (T) and after coprecipitation to give the "precipitable lead" (P) using the method of Cholak et al. (1948). All the subjects with increased lead absorption as well as the majority of the normals were admitted to our Occupational Disease Clinic for the duration of this investigation. Urinary lead determinations were repeated frequently under carefully controlled conditions.

\section{Results}

The average values of the total urinary lead $(T)$ and the precipitable lead (P) for the three groups of people observed are given in Table 1.
Furthermore the non-precipitable fraction in general increases with the magnitude of the total urinary lead excretion. When calculated as a percentage of the true lead elimination the nonprecipitable lead is negligible for normal individuals but rises to $41.6 \%$ in cases of chronic lead poisoning (Table 1, Column 5).

The differences can be expressed more strikingly by considering the relation $\frac{\text { total } \mathrm{Pb}}{\text { precipitable } \mathrm{Pb}}\left(\frac{\mathrm{T}}{\mathrm{P}}\right)$ within each group. The weighted average, $\frac{T}{\mathbf{P}}$, together with the standard deviation, as well as the standard errors of the differences between the averages of the exposed groups and the normals, are shown in Table 2.

The small standard deviation for the normals reflects the homogeneity of that group with respect to urinary lead excretions. The other categories show a somewhat greater scatter of individual values which is not unexpected in groups established on

TABLE 1

WEIGHTED AVERAGES OF URINARY LEAD ( $\mu$ g. Pb/litre) DETERMINED BY TWO METHODS IN THREE GROUPS OF SUBJECTS

\begin{tabular}{|c|c|c|c|c|c|}
\hline \multirow{2}{*}{ Degree of Lead Exposure } & \multirow{2}{*}{ No. of Cases } & \multicolumn{2}{|c|}{ Lead Content } & \multirow{2}{*}{$\begin{array}{c}\text { Non-precipitable } \\
\text { Lead T-P }\end{array}$} & \multirow{2}{*}{$\begin{array}{l}T-P \\
\text { as } \% \text { of } T\end{array}$} \\
\hline & & $(T)^{*}$ & (P) & & \\
\hline $\begin{array}{l}\text { Normal } \\
\text { Increased absorption } \\
\text { Chronic evolutive lead poisoning }\end{array}$ & $\begin{array}{l}44 \\
15 \\
57\end{array}$ & $\begin{array}{r}43 \cdot 0 \\
130 \cdot 4 \\
256 \cdot 9\end{array}$ & $\begin{array}{c}42 \cdot 6 \\
95 \cdot 5 \\
150 \cdot 04\end{array}$ & $\begin{array}{c}0.4 \\
34 \cdot 9 \\
106 \cdot 86\end{array}$ & $\begin{array}{r}0.93 \\
26.80 \\
41 \cdot 61\end{array}$ \\
\hline
\end{tabular}

*Total lead $(T)=$ Determined after acid digestion; precipitable lead $(P)=$ determined after coprecipitation.

It will be noted that for the normal the precipitable lead values are virtually identical with the total lead estimated after ashing, showing that coprecipitation can separate the lead quantitatively from the urine. On the other hand, individuals exposed to lead have values of precipitable lead which are less than the true urinary lead level obtained by the ashing technique. The difference between the two values may represent a considerable proportion of the total lead excreted. The low value of urinary lead found in cases of lead poisoning can thus be explained by the inability of the coprecipitation method to estimate quantitatively the urinary lead. such broad criteria. Nevertheless the homogeneity in these groups is statistically satisfactory. The values for each of the cases studied in the three groups are presented in Fig. 1.

Among the cases of lead poisoning those individuals with lead colic had in general a higher urinary lead excretion but the proportion of nonprecipitable lead was practically the same as for the group as a whole.

Having established the presence of lead in two different chemical forms in the urine of subjects exposed to lead we had next to consider their chemical characteristics. This non-precipitable fraction has

TABLE 2

WEIGHTED AVERAGE OF RATIO $\frac{T}{P}$ FOR URINARY LEAD IN THREE GROUPS OF SUBJECTS

\begin{tabular}{|c|c|c|c|c|c|}
\hline Degree of Lead Exposure & No. of Cases & $\mathbf{T} / \mathbf{P}$ & S.D. & ${ }^{*} \mathbf{S M}_{1}-\mathbf{M}_{2}$ & $+\mathbf{S M}_{1}^{\prime}-\mathbf{M}_{2}^{\prime}$ \\
\hline $\begin{array}{l}\text { Normal } \\
\text { Increased absorption } \\
\text { Chronic evolutive lead poisoning }\end{array}$ & $\begin{array}{l}44 \\
15 \\
57\end{array}$ & $\begin{array}{l}1.01 \\
1.47 \\
1.93\end{array}$ & $\begin{array}{l}0.099 \\
0.411 \\
0.877\end{array}$ & $\begin{array}{l}4 \cdot \overline{29} \\
7 \cdot 77\end{array}$ & $\overline{\bar{Z}} \overline{\mathrm{94}}$ \\
\hline
\end{tabular}

* $\mathrm{SM}_{1}-\mathrm{M}_{2}=$ "normal" relatively to "increased absorption" and "chronic evolutive lead poisoning" categories.

†S $\mathbf{M}^{\prime}{ }_{1}-\mathbf{M}_{2}=$ "increased absorption" relatively to "chronic evolutive lead poisoning" category. 

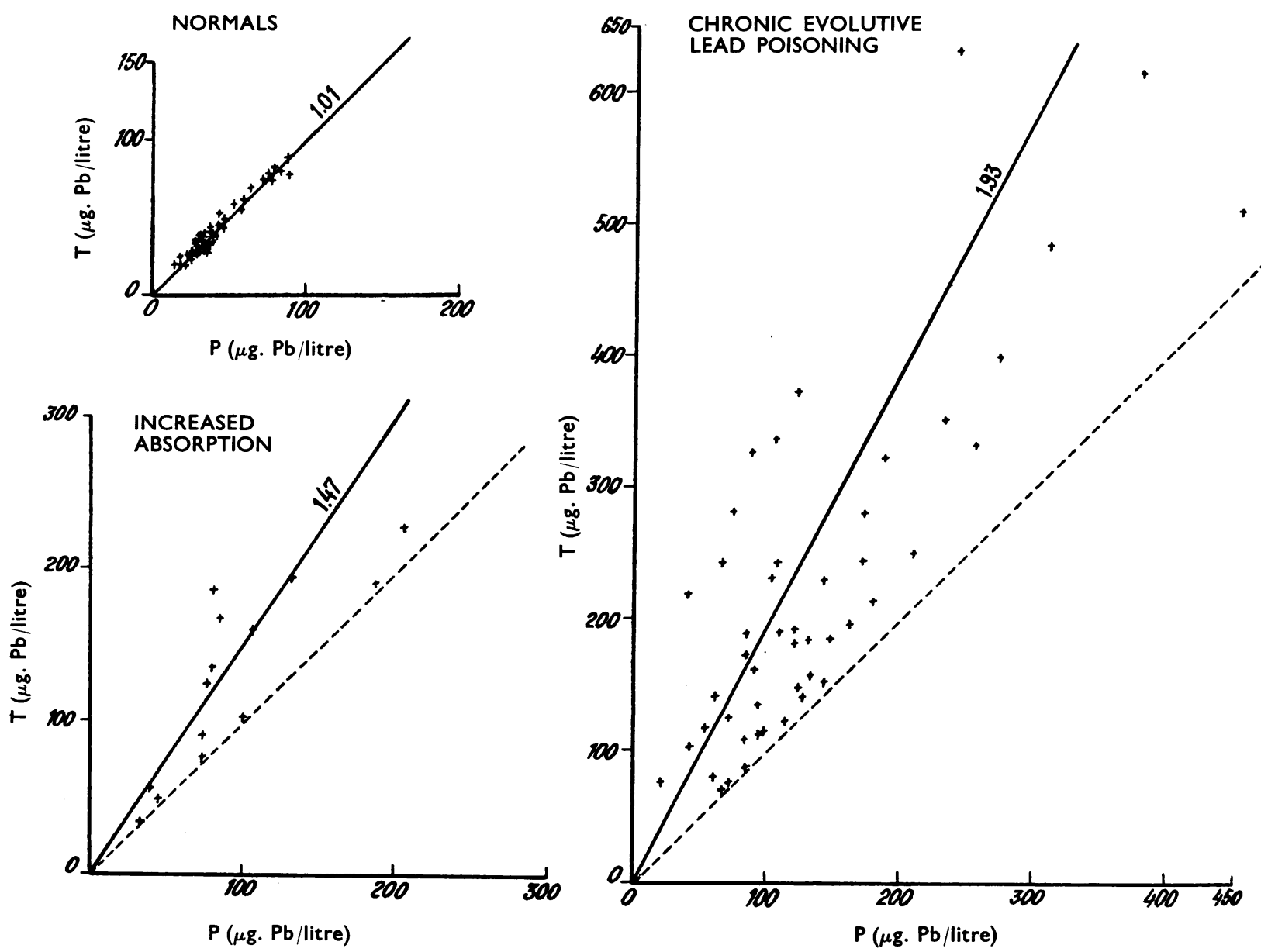

$\mathrm{P}(\mu \mathrm{g} . \mathrm{Pb} /$ litre)

$\mathrm{P}(\mu \mathrm{g} . \mathrm{Pb} /$ litre $)$

Fig. 1.-The ratio $\frac{T}{P}$ for the lead in the urine of individual cases in the three groups of subjects (see Table 1). Continuous line $=$ weighted average $\frac{T}{P} \quad$ Each dot: average $\frac{T}{P}$ for individuals.

not hitherto been investigated. Our own limited lead in both forms was known was shaken with observations may be briefly described. Urine from cases of chronic poisoning in which the content of activated alumina (Brockmann) and the total and precipitable lead in the supernatant estimated. The

TABLE 3

LEAD CONTENT OF SIX SAMPLES OF URINE ( $\mu \mathrm{g}$. Pb/litre) DETERMINED BEFORE AND AFTER ADSORPTION $\mathrm{ON} \mathrm{Al}_{2} \mathrm{O}_{3}$

\begin{tabular}{|c|c|c|c|c|c|}
\hline \multirow{3}{*}{ Sample } & \multicolumn{5}{|c|}{ Urine } \\
\hline & \multicolumn{3}{|c|}{ Before Adsorption } & \multicolumn{2}{|c|}{ After Adsorption } \\
\hline & $\begin{array}{c}\text { Total Pb } \\
\text { (T) }\end{array}$ & $\underset{\text { (P) }}{\text { Precipitable } \mathbf{P b}}$ & $\underset{(T-P)}{\text { Non-precipitable } \mathbf{P b}}$ & $\underset{\text { (T) }}{\text { Total Pb }}$ & $\begin{array}{c}\text { Precipitable Pb } \\
\text { (P) }\end{array}$ \\
\hline $\begin{array}{l}\mathrm{RT} \\
\mathrm{TC} \mathbf{1}_{1} \\
\mathrm{AI}_{1} \\
\mathrm{BI}_{1} \\
\mathrm{TC}_{\mathbf{1}} \\
\mathbf{6 4 5}\end{array}$ & $\begin{array}{r}135.0 \\
139.0 \\
71.0 \\
60.0 \\
120.0 \\
105.0\end{array}$ & $\begin{array}{r}120.0 \\
82.5 \\
52.5 \\
30.0 \\
37.5 \\
37.5\end{array}$ & $\begin{array}{l}15.0 \\
56.5 \\
18.5 \\
30.0 \\
82.5 \\
67.5\end{array}$ & $\begin{array}{l}15.0 \\
49.0 \\
15.0 \\
30.0 \\
64.0 \\
52 \cdot 5\end{array}$ & $\begin{array}{l}0.0 \\
0.0 \\
0.0 \\
0.0 \\
0.0 \\
0.0\end{array}$ \\
\hline
\end{tabular}

5 
TABLE 4

LEAD CONTENT OF URINE ( $\mu$ g. Pb/litre) BEFORE AND AFTER DIALYSIS AGAINST WATER THROUGH CELLOPHANE

\begin{tabular}{|c|c|c|c|c|}
\hline \multirow{3}{*}{ Sample } & \multicolumn{4}{|c|}{ Urine } \\
\hline & \multicolumn{3}{|c|}{ Before Dialysis } & \multirow{2}{*}{$\begin{array}{c}\text { After Dialysis } \\
\text { Total Lead } \\
\text { (T) }\end{array}$} \\
\hline & $\begin{array}{l}\text { Total Lead } \\
\text { (T) }\end{array}$ & $\begin{array}{c}\text { Precipitable Lead } \\
\text { (P) }\end{array}$ & $\begin{array}{c}\text { Non-precipitable Lead } \\
(\mathbf{T}-\mathbf{P})\end{array}$ & \\
\hline $\begin{array}{l}\mathbf{B C} \\
\mathbf{U D} \\
\mathbf{A} \mathbf{M} \\
\mathbf{B I}_{\mathbf{2}} \\
\mathbf{A} \mathbf{I}_{\mathbf{2}}\end{array}$ & $\begin{array}{r}310.0 \\
124.0 \\
187.5 \\
150.0 \\
90.0\end{array}$ & $\begin{array}{r}244.0 \\
30.0 \\
120.0 \\
82.5 \\
37.5\end{array}$ & $\begin{array}{l}66 \cdot 0 \\
94 \cdot 0 \\
67 \cdot 5 \\
67 \cdot 5 \\
52 \cdot 5\end{array}$ & $\begin{array}{l}60.0 \\
86.0 \\
57.0 \\
60.0 \\
50.0\end{array}$ \\
\hline
\end{tabular}

results in Table 3 indicate that the precipitable lead was entirely adsorbed on the alumina but the nonprecipitable fraction remained in solution. This indicates that the precipitable fraction of urinary lead is ionized, probably as lead phosphate, while the non-precipitable lead is in some organic combination. In further tests urine was dialysed against lead-free distilled water through commercial cellophane until it was free from chloride.

The non-dialysable lead is seen to be almost the same as the quantity of non-precipitable lead (Table 4).

These preliminary results suggest that the nonprecipitable fraction of urinary lead is bound to weakly polar molecules, possibly a natural chelate. This is being further investigated, and the view is supported by recent attempts to identify a lead chelate in human urine (Nelson and Hamm, 1958).

\section{Discussion}

The data obtained by parallel estimations of the two forms of urinary lead show some points of special interest. In normal subjects where the amount of lead absorbed equals that which is excreted the urinary lead is eliminated entirely as precipitable lead. But where there is increased absorption with or without lead poisoning the urinary lead appears in two forms. The nonprecipitable lead found only in urine of subjects exposed to lead appears thus to distinguish this category from those with only a physiological absorption.

The level of non-precipitable urinary lead increases with the total lead excretion and is highest in those suffering from lead poisoning. However, the principal condition governing the excretion of this non-precipitable lead fraction is not so much the severity of the clinical state of those suffering from lead poisoning but rather the degree of lead accumulation which may be found equally in those not suffering from clinical lead poisoning.

From prolonged observation of the urinary lead excretion in some cases of chronic lead poisoning in hospital we found that the proportion of non- precipitable lead decreased more rapidly than the remission of the illness, indicating that the decrease was most probably related to an interruption of an abnormally high rate of lead absorption. This further supports our view that the presence of nonprecipitable lead in the urine is related in the first place to the process of lead accumulation. This poses interesting problems concerning the physiopathology of lead poisoning. The chemical nature of the non-precipitable fraction, together with its origin and biological significance, requires further elucidation. It may represent a product of an altered metabolism or a special form in which lead is transported under conditions of high rates of absorption. The lead circulation in the body consisting of successive fixation, mobilization, transportation, and accumulation (Teisinger, 1935; Kety, 1942) may possibly be analogous to the better known processes of absorption, transportation, and fixation of iron. The firm or labile binding of blood zinc on an organic carrier (Wolff, 1956) may also be compared to our findings with lead. The possibility of a similar behaviour in other heavy metals is also suggested.

From the diagnostic point of view this clear-cut differentiation of the forms in which lead is excreted in the urine will be useful. The finding of a significant fraction of non-precipitable urinary lead may be the first sign of a toxic accumulative process which has not yet been expressed in any clinical or haematological evidence. The absolute values and the percentage of the total lead represented by the non-precipitable fractions could give a more adequate index for the appraisal of the degree of intoxication and its evolution.

Finally, the behaviour of this urinary lead fraction being more closely dependent on lead accumulation may express more directly the level of exposure than does the presence of basophilic blood cells or urinary coproporphyrins.

Our observations also have important practical implications regarding the value of the coprecipitation method of urinary lead estimation used for the screening of exposed workers or in the diagnosis of 
patients. In cases in which lead absorption is high, the urinary lead measured by this method will appear too low and as a result a proportion of men in danger of lead poisoning or already poisoned may escape detection if clinical signs and other laboratory tests are not sufficiently convincing. This underlines the need for an analytical procedure which estimates all the lead in the urine.

\section{REFERENCES}

Amdur, M. O. (1953). A.M.A. Arch. industr. Hyg., 7, 277.

Bessman, S. P., and Layne, E. C. (1955), J. Lab. clin. Med., 45, 159 Cholak, J., Hubbard, D. M., and Burkey, R. E. (1948). J. industr. Hyg., 30, 59.
Dinischiotu, G. T., Rădulescu, I. C., Preda, N., and Georgescu, A. M. (1959). Arch. Gewerbepath. Gewerbehyg., 17, 127.

Fairhall, L. T. (1924). J. biol. Chem., 60, 485.

G, and Keenan, R. G. (1941). J. Amer. chem. Soc., 63, 3076

Gorn, L. E., and Fridland, I. G. (1955). Gig. $i$ Sanit., No. 5, p. 44.

Hardy, H. L., Elkins, H. B., Ruotolo, B. P. W., Quinby, J., and Baker, W. H. (1954).' J. Amer. med. Ass., 154, 1171.

Kaye, S. (1943). J. Lab. clin. Med., 28, 1171.

Kehoe, R. A. Thamann, F., and Cholak, J. (1933a). J. industr. Hyg., $15,306$.

Kety S.S (1942) (1933b). Ibid., 15, 320.

Litzner, S., and Weyrauch, F. (1932). Arch. Gewerbepath. Gewerbehyg. 4, 74.

Nelson, K. W., and Hamm, R. E. (1958). A.M.A. Arch. industr. Hlth, $17,38$.

Rosenqvist, I. T. (1942). Amer. J. Sci., 240, 356.

Teisinger, J. (1935). Biochem. Z., 277, 178.

Woessner, W. W., and Cholak, J. (1953). A.M.A. Arch. industr. Wolf, Hy. P. (1956). Klin. Wschr., 34, 409. 